\title{
Cost Effectiveness of Cladribine Tablets for the Treatment of Relapsing-Remitting Multiple Sclerosis in The Netherlands
}

\author{
Renée Else Michels ${ }^{1} \cdot$ Maria de Fransesco $^{2} \cdot$ Koshu Mahajan $^{3} \cdot$ Gerald J. D. Hengstman $^{4} \cdot$ Krijn M. H. Schiffers $^{5}$. \\ Sangeeta Budhia ${ }^{6} \cdot$ Gerard Harty $^{7} \cdot$ Marieke Krol $^{1}$ (i)
}

Published online: 23 August 2019

(c) The Author(s) 2019

\begin{abstract}
Background Cladribine tablets have recently become available in The Netherlands for patients with relapsing-remitting multiple sclerosis (RRMS) as a disease-modifying agent that reduces the frequency and severity of relapses and delays disability progression.

Objective The aim of this study was to evaluate the cost effectiveness of cladribine tablets, compared with alternative options, in the treatment of RRMS patients with high disease activity (HDA) and patients with rapidly evolving severe (RES) MS in The Netherlands.

Methods A Markov model was developed simulating the costs and effects of RRMS treatment. For HDA, alemtuzumab and fingolimod were used as comparators; natalizumab was used for the RES subpopulation. The analysis included a societal perspective and a value-of-information (VOI) analysis.

Results For the HDA subpopulation, treatment with cladribine tablets was the cost-effective (dominant) strategy compared with alemtuzumab and fingolimod, with $50.9 \%$ and $98.2 \%$, respectively, probability of being cost effective at a threshold of $€ 50,000 / \mathrm{Q} A L Y$ gained and a net monetary benefit (NMB) of $€ 10,866$ and $€ 151,115$, respectively. For the RES subpopulation, treatment with cladribine tablets dominated treatment with natalizumab, with $94.1 \%$ probability of being cost effective at a threshold of $€ 50,000 /$ QALY gained and an NMB of $€ 122,986$. Note that these outcomes are driven by the lower costs of cladribine tablets. Efficacy differences were small, very uncertain, and likely not clinically meaningful. The probabilistic sensitivity analyses showed significant overlap in the credible intervals for total lifetime QALY outcomes and costs of cladribine tablets and all relevant comparators. The population-level VOI amounted to $€ 19,295,441$.

Conclusions The base-case analysis shows that treatment of RRMS with cladribine tablets is cost effective versus alemtuzumab and fingolimod in HDA patients, and cost effective versus natalizumab in RES patients, at a threshold of $€ 50,000$. Driven by the lower costs, cladribine tablets were cost effective (dominant) in all base-case analyses. However, given that outcomes are based on indirect comparisons and post hoc subgroup analysis, as well as the uncertainty surrounding the outcomes, the results presented in this paper should be interpreted with caution.
\end{abstract}

Electronic supplementary material The online version of this article (https://doi.org/10.1007/s40258-019-00500-8) contains supplementary material, which is available to authorized users.

Marieke Krol

mkrol@iqvia.com

1 IQVIA, Real World Evidence Solutions, Herikerbergweg 314, 1101 CT Amsterdam, The Netherlands

2 IQVIA, Real World Insights, Da Vincilaan 7, 1930 Zaventem, Belgium

3 IQVIA, Real World Insights, Gurgaon, India
4 Department of Neurology, Catharina Hospital, Michelangelolaan 2, 5623 EJ Eindhoven, The Netherlands

5 Merck B.V., Tupolevlaan 41-61, 1119 NW Schiphol-Rijk, The Netherlands

6 PAREXEL International, PAREXEL Access Consulting, London, UK

7 EMD Serono, a business of Merck KGaA, Boston, MA, USA 


\section{Key Points for Decision Makers}

This model is the first example of assessing the cost effectiveness of cladribine tablets versus other diseasemodifying drugs (DMDs) in the treatment of patients with relapse-remitting multiple sclerosis (RRMS) in The Netherlands.

The model allowed for analysis from a full societal perspective, including indirect medical costs, productivity costs, and costs for informal care.

Cladribine tablets were estimated to be a cost-effective treatment for patients with RRMS and high disease activity/rapidly evolving severe disease compared with the current standard of care in The Netherlands.

These analyses show drug costs are the main driver of differences in cost effectiveness between treatments.

Given that outcomes are based on indirect comparisons and post hoc subgroup analysis, as well as the uncertainty surrounding the outcomes, the results presented in this paper should be interpreted with caution.

\section{Introduction}

Multiple sclerosis (MS) is a chronic and degenerative neurological condition that is associated with neurological impairment, severe disability, and premature mortality [1]. In a population-based study specific to The Netherlands, the overall age-sex standardized incidence rate of MS was 4.8/100,000 person-years and prevalence was estimated to be 1 in 1000 patients [2]. Most patients will experience the initial symptoms of disease upon diagnosis during early adulthood; the symptoms can progress rapidly and approximately $50 \%$ of patients will eventually require assistance to walk and will be confined to a wheelchair or bed. Since there are currently no curative interventions, the condition will persist throughout the life of the person with MS [3].

There are two broad categories for MS - relapsing disease and progressive disease. Relapsing disease is categorized in clinically isolated syndrome (CIS) and relapsing-remitting multiple sclerosis (RRMS), whereas progressive disease is categorized in progressive accumulation of disability from onset (primary progressive; PP) and progressive accumulation of disability after initial relapsing course (secondary progressive; SP) [4]. The relapsing phase is characterized by the occurrence of relapses that have a tendency over time to remit. Relapses may result in an increase in disability because remittance is not always complete, depending on the period of remission [5, 6]. On average, relapses occur once or twice a year and are associated with inflammation and the development of new focal lesions. Over time, approximately $90 \%$ of patients with RRMS will develop SPMS, which is characterized by fewer relapse events and a gradual progression in disability between relapses [7]. The RRMS phenotype is of primary interest for this article, with special focus on high disease activity (HDA) and rapidly evolving severe (RES) subpopulations.

Progression to advanced stages of the disease has a significant impact on the health-related quality of life (HRQoL) of patients and their caregivers, and can lead to a significant cost burden to payers and society $[1,2,8]$. Available Dutch MS guidelines [9] advise a multidisciplinary approach to care, including support from neurologists, MS nurses, and therapists. This supportive care is provided alongside pharmacological therapy, which includes the treatment of symptoms of disability progression and the use of disease-modifying drugs (DMDs) [10]. The goal of therapy with DMDs is to reduce the frequency and severity of relapse events and to delay disability progression. There are currently 11 approved DMDs for MS. At the time of model adaptation, the most recently approved products currently reimbursed in The Netherlands for the treatment of RRMS with HDA/ RES were alemtuzumab, fingolimod, and natalizumab [9].

Cladribine tablets $\left(\right.$ Mavenclad $\left.^{\circledR}\right)$ are an oral DMD approved by the European Medicines Agency (EMA) in August 2017. Cladribine is a preferential lymphocytedepleting therapy that has a unique posology involving only two short treatment courses over a 2-year period, followed by at least 2 years of disease monitoring. The results of the phase III trials, CLARITY and CLARITY EXT (RRMS), demonstrate that treatment with cladribine tablets is associated with a significant reduction in the annualized relapse rate (ARR), an increase in the proportion free of relapse, and a significant reduction in the risk of 3- and 6-month EDSS progression compared with patients treated with placebo $[11,12]$. While the cost effectiveness of cladribine tablets versus existing DMDs for RRMS has been assessed for the UK [13], no such study has been conducted for The Netherlands. The aim of this study was to evaluate the cost effectiveness of cladribine tablets compared with alemtuzumab and fingolimod for patients with RRMS and HDA, and compared with natalizumab for patients with RES RRMS in The Netherlands. ${ }^{1}$ This is the first time a societal perspective has also been included in a cost-effectiveness evaluation of cladribine tablets.

\footnotetext{
1 The HDA subpopulation is defined as either [1] patients with at least one relapse in the previous year while receiving DMD therapy, and either at least one $\mathrm{T} 1 \mathrm{Gd}+$ lesions or at least nine $\mathrm{T} 2$ lesions; or (b) patients with two or more relapses in the prior year, whether receiving treatment or not. The RES subpopulation is defined as [1] patients with two or more relapses in the prior year, whether receiving treatment or not; and (b) patients with at least one $\mathrm{T} 1 \mathrm{Gd}+$ lesion.
} 
Table 1 Baseline characteristics of the study populations in the model (CLARITY study)

\begin{tabular}{|c|c|c|}
\hline Characteristic & HDA population & RES population \\
\hline Mean age at treatment, (years) & 37.1 & 33.3 \\
\hline Standard error & 0.836 & 1.281 \\
\hline Female to male ratio & 1.709 & 1.412 \\
\hline Number of relapses in the prior year & 2.020 & 2.244 \\
\hline Average patient weight, $(\mathrm{kg})$ & 69.72 & 69.29 \\
\hline \multicolumn{3}{|l|}{ Weight distribution, $\mathrm{kg}(\%)$} \\
\hline $40-50$ & 6.2 & 9.9 \\
\hline $50-60$ & 21.5 & 17.6 \\
\hline $60-70$ & 29.4 & 34.1 \\
\hline $70-80$ & 20.4 & 15.4 \\
\hline $80-90$ & 10.0 & 8.8 \\
\hline $90-100$ & 6.9 & 8.8 \\
\hline $100-110$ & 3.5 & 4.4 \\
\hline$>110 \mathrm{~kg}$ & 2.1 & 1.1 \\
\hline \multicolumn{3}{|l|}{ Distribution over EDSS states (\%) } \\
\hline EDSS 0 & 2.8 & 4.4 \\
\hline EDSS 1.0 & 2.8 & 3.3 \\
\hline EDSS 2.0 & 32.5 & 31.9 \\
\hline EDSS 3.0 & 21.5 & 20.9 \\
\hline EDSS 4.0 & 23.5 & 23.1 \\
\hline EDSS 5.0 & 11.1 & 11.0 \\
\hline EDSS 6.0 & 5.9 & 5.5 \\
\hline EDSS 7.0 & 0.0 & 0.0 \\
\hline EDSS 8.0 & 0.0 & 0.0 \\
\hline EDSS 9.0 & 0.0 & 0.0 \\
\hline Sample $(n)$ & 289 & 91 \\
\hline References & Giovannoni et al. [32] & Giovannoni et al. [32] \\
\hline
\end{tabular}

$H D A$ high disease activity, RES rapidly evolving severe, EDSS Expanded Disability Status Scale

\section{Methods}

To meet the aim of this study, a previously constructed health economic model [13] was adapted to meet the requirements of the Dutch Healthcare Institute and to reflect Dutch clinical practice, meaning that Dutch HRQoL and cost inputs were implemented, and some structural changes were made to include indirect non-medical and medical costs, as well as direct non-medical costs and a value of information (VOI) analysis. Model inputs were validated by means of a face-to-face expert with a Dutch key opinion leader (KOL) in MS treatment.

\subsection{Study Population and Comparators}

Given the approved indication for treatment with cladribine tablets, the population of interest was patients with RRMS and HDA. The relevant comparators in The Netherlands that were included in the analyses were fingolimod, alemtuzumab, and natalizumab as these three DMDs are specifically used in The Netherlands for the treatment of RRMS with HDA/RES [14]. These comparators were also validated by a clinical KOL. Data for RRMS patients with HDA were not available for all comparators included in the analysis (natalizumab); therefore, the RES RRMS subpopulation was also considered in this study as natalizumab is only used in the RES population in The Netherlands.

Baseline characteristics in the model were obtained from the placebo arm of the CLARITY phase III study (Table 1). The relevance of these characteristics for the Dutch patient population was confirmed by a Dutch KOL with experience in MS.

\subsection{Model Structure}

A cohort-based multi-state Markov transition model was developed in Microsoft Excel (Microsoft Corporation, Redmond, WA, USA) to simulate the costs and effectiveness of treatment in people with RRMS [13]. This model was based on two mathematical models-a natural history reference model, developed using data on the disability progression and relapse status of people receiving best supportive care 


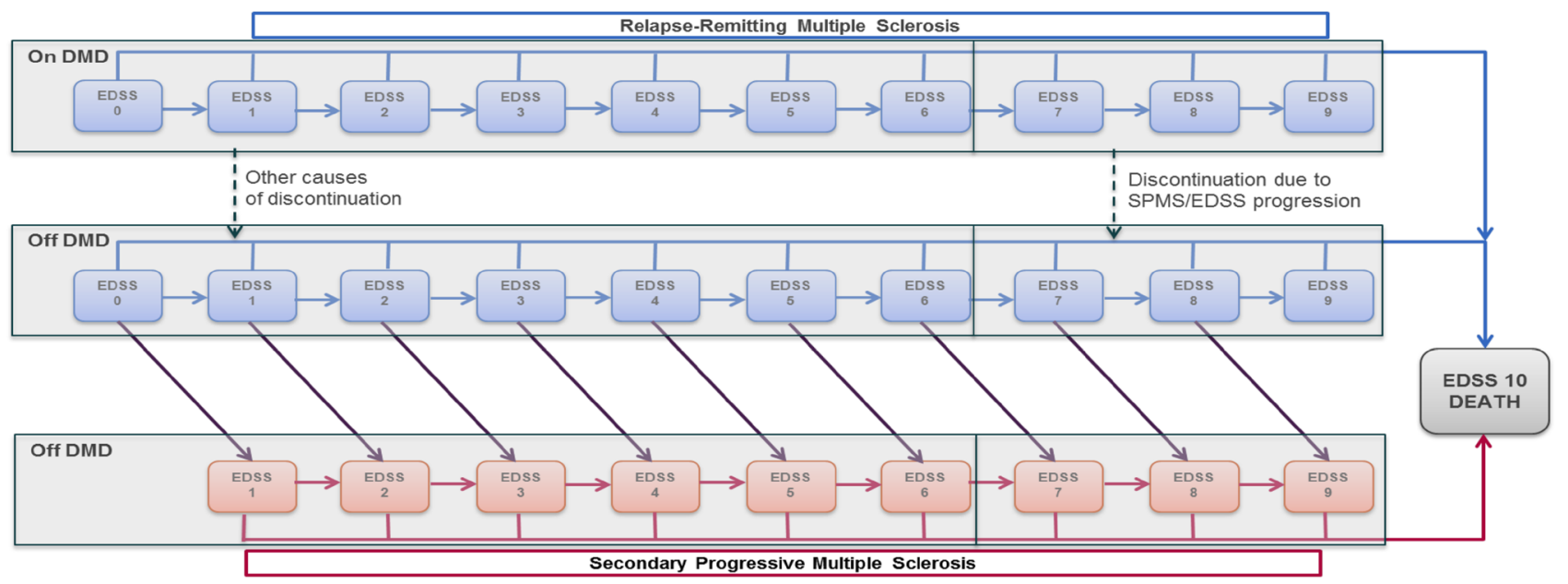

DMD: Disease Modifying Drug, EDSS: Expanded Disability Status Scale, SPMS: Secondary Progressive Multiple Sclerosis.

Fig. 1 Health state structure of the 21-state model including periods on and off DMDs

(BSC), and a treatment-adjusted model, which combines the reference model with data on the comparative efficacy and safety of the various DMDs versus placebo. The natural history model has data for generic RRMS, whereas the treatment-adjusted model incorporates the distinction between HDA and RES. Disease progression was modeled using the Kurtzke Expanded Disability Status Scale (EDSS) system, presented in a 21-health-state structure comprising 10 EDSS states for RRMS, 10 EDSS states for SPMS, and 1 death state (general mortality). This is an established disability rating scale that ranges from 0 (normal health) to 10 (death due to MS), where increasing scores indicate greater clinical disability [15]. The scale measures a range of functional issues, including bowel and bladder function, visual function, and mobility, and is the primary instrument used to evaluate the clinical disability of people with MS. The model explicitly accounts for differences in the disability progression rate and quality of life between the RRMS and SPMS phases. The 21-health-state structure is based on the assessment group model developed for the National Institute for Health and Care Excellence (NICE) TA32 [16], a multiple technology appraisal of $\beta$-interferon and glatiramer acetate in RRMS [16] (an illustration of the 21-health-state structure is provided in Fig. 1). The model structure was validated by the Dutch KOL, who indicated that it was appropriate to differentiate between progression rates in RRMS and SPMS.

At the start of the evaluation, the patient cohort is proportionally assigned to the 10 RRMS EDSS states in the model, according to the baseline EDSS distribution in the CLARITY study (Table 1). Over time, the cohort is at risk of experiencing disability progression (move to a higher EDSS state), improving disability status (move to a lower
EDSS state), remaining at their current level of disability (remain in their current EDSS state), converting to SPMS, or dying. Progression to SPMS is associated with a 1-point increase in EDSS. Please note that there has been some debate by the NICE Evidence Review Group on this point, however previous NICE appraisals deemed the assumption of a 1-point increase in EDSS to be an appropriate reflection if increasing disability experiences upon progression to an SPMS disease course (for instance, see page 10 of NICE TA493 [52]). The treatment-adjusted model was created by combining the natural history reference model with the comparative efficacy and safety of DMDs versus placebo. Treatment with a DMD is assumed to impact the following outcomes: decrease the probability of progressing in an EDSS state over time, decrease the annualized rate of relapse, and increase or decrease the incidence of drugrelated adverse events. In each model cycle, patients taking DMDs were at risk of discontinuing treatment from loss of efficacy, loss of tolerability, progression to EDSS $\geq 7.0$, or development of SPMS. This is in line with the recommendations of the Association of British Neurologists advising clinicians when they should consider stopping treatment. It was assumed that any patient transitioning to an EDSS state $\geq 7.0$ would be considered to have SPMS, and hence discontinued from therapy. This is in line with approaches taken in previous models [13].

As is required by Dutch health economic guidelines published by the Dutch Healthcare Institute [17], the model takes a societal perspective. In addition to direct medical costs, the model considers productivity loss, informal care, and unrelated medical costs. Given the chronic nature of MS, a time horizon of 50 years (close to a lifetime) was used 
and the cycle length was set to 1 year, representing enough time to observe changes in RRMS disease progression and corresponding with time points of clinical studies of interest. Half-cycle correction ${ }^{2}$ was performed and annual discount rates of $4 \%$ and $1.5 \%$ were applied to costs and outcomes, respectively [17]. Outcomes measured as cost per incremental QALY were compared with the reference values set out by the Dutch Healthcare Institute to determine whether an intervention was considered cost effective. The Healthcare Institute considers a willingness to pay (WTP) reference value of either $€ 20,000 /$ QALY (for treatment of illnesses with a low disease severity), €50,000/QALY (medium disease severity), or $€ 80,000 / \mathrm{QALY}$ (for high disease severity) [18]. Although the disease severity of RRMS with HDA can be considered high, the more conservative $€ 50,000 / \mathrm{QALY}$ was applied as the reference value.

\subsection{Model Inputs}

\subsubsection{Clinical}

The model included clinical inputs for EDSS transition, conversion to SPMS, relapse rate, mortality rate, and inputs related to treatment, such as comparative efficacy, waning effect, adverse events, and probability of discontinuation. The treatment effect was based on post hoc subgroup analysis. The effect for each DMD derived from a network metaanalysis conducted on aggregated clinical trial data identified from a systematic literature review [19] (see Table 2). In addition, a meta regression analysis was conducted, extrapolating the effect size estimates from the active RRMS population to the RES group by relating efficacy to baseline risk and centering baseline risk to the expected value in each group [20].

For the natural history model, movement between the RRMS EDSS states was taken from the British Columbia Multiple Sclerosis (BCMS) registry [21] (Table 3). For conversion from RRMS to SPMS, data from the study by Koch et al., which reported the natural history of SPMS, were used [22]. In their study, Kock et al. report the results of a retrospective Kaplan-Meier and Cox regression analysis of the time to and age at SPMS in untreated people registered in the BCMS dataset. The generalized gamma was selected as the preferred survival function for the model because of its

\footnotetext{
2 Please note that half-cycle correction is a standard approach by HTA agencies to mitigate the risk of under- or overestimating costs and effects. EDSS and drug-related costs and QALY are modeled based on midpoint estimates, assuming patients, on average, transition mid-way through the annual model cycle. Exceptions are the drug costs of cladribine tablets and alemtuzumab, which are assumed to accrue at the start of the model cycle as therapy is given as a fixed course at the beginning of each cycle.
}

Table 2 Efficacy risk ratios for cladribine tablets versus comparators, from the network meta-analyses [19]

\begin{tabular}{lc}
\hline Annualized relapse rate & \\
\hline Cladribine tablets vs. & RR $(95 \% \mathrm{CrI})$ \\
\hline Alemtuzumab $12 \mathrm{mg}$ qd & $1.30(0.93-1.83)$ \\
Fingolimod $0.5 \mathrm{mg}$ qd & $0.91(0.67-1.22)$ \\
Natalizumab $300 \mathrm{mg} \mathrm{q} 4 \mathrm{w}$ & $1.22(0.89-1.68)$ \\
\hline Confirmed disease progression sustained for 6 months at 24 months \\
\hline Cladribine tablets vs. & HR $(95 \% \mathrm{CrI})$ \\
\hline Alemtuzumab $12 \mathrm{mg}$ qd & $1.37(0.58-3.32)$ \\
Fingolimod $0.5 \mathrm{mg}$ qd & $0.79(0.37-1.64)$ \\
Natalizumab $300 \mathrm{mg} \mathrm{q} 4 \mathrm{w}$ & $1.21(0.52-2.77)$ \\
\hline
\end{tabular}

$R R$ relapse rate, $C r I$ credible interval, $H R$ hazard ratio, $q d$ once daily, $q 4 w$ every 4 weeks

${ }^{a}$ Confirmed disease progression measures the increase in a patient's disease progression over a predetermined time period, in this case 6 months

goodness of fit for data for both men and women. Due to the lack of data, the same SPMS conversion rates were assumed to apply across all HDA and RES populations. Progression rates within the SPMS states were taken from the London Ontario registry [23].

The relapse rate was modeled independently of the EDSS state as studies show that these can occur separately from EDSS progression [24, 25]. Relapse events are calculated by applying an ARR to the number of patients alive in the model. The ARR is not constant but rather caries over time based on a proportional annual reduction $(5.07 \%)$ calculated from data reported by Tremlett et al. [26, 27]. The baseline relapse rate is based on the rate observed in the placebo arm of the CLARITY study and is population-specific. Given that there was no notable difference between the relapse rate of patients treated with alemtuzumab or cladribine tablets, the ARR of alemtuzumab was set equal to cladribine tablets in the HDA population. This assumption is based on the fact that at the time of submission of both the model and the paper, no possible link was available for the ARR in HDA for alemtuzumab, but a possible link was available for natalizumab and fingolimod. The mortality rate is modeled to vary over time in line with aging of the cohort, and is estimated using all-cause sex- and age-matched mortality statistics that are inflated to account for the higher mortality rate associated with MS [28, 29].

The waning effect reflects the uncertainty in the longerterm benefits of drug therapy. It is assumed that the full effect of cladribine tablets is sustained through years $0-2$, is assumed to wane from 100 to $75 \%$ in years $2-3$, and is assumed to reach $50 \%$ from years $4-5$ onwards. No further waning is assumed after year 5 . The same waning effects are assumed for the comparators. The waning effects used in this 
Table 3 Annual transition probabilities (RRMS age of onset $\geq 28$ years, and SMPS)

\begin{tabular}{|c|c|c|c|c|c|c|c|c|c|c|c|c|}
\hline & From/to & 0 & 1 & 2 & 3 & 4 & 5 & 6 & 7 & 8 & 9 & Sample size \\
\hline \multirow[t]{10}{*}{ RRMS (EDSS score) } & 0 & 69.5 & 20.3 & 7.3 & 2.2 & 0.4 & 0.1 & 0.2 & 0.0 & 0.0 & 0.0 & 326 \\
\hline & 1 & 5.8 & 69.5 & 15.8 & 6.1 & 1.6 & 0.5 & 0.6 & 0.0 & 0.0 & 0.0 & 317 \\
\hline & 2 & 1.6 & 12.1 & 60.8 & 16.8 & 4.5 & 1.8 & 2.2 & 0.2 & 0.1 & 0.0 & 317 \\
\hline & 3 & 0.6 & 5.0 & 12.0 & 54.4 & 9.1 & 5.8 & 11.6 & 1.0 & 0.4 & 0.0 & 317 \\
\hline & 4 & 0.2 & 2.2 & 6.7 & 11.5 & 48.9 & 10.4 & 16.8 & 2.6 & 0.7 & 0.1 & 317 \\
\hline & 5 & 0.1 & 0.5 & 2.9 & 5.9 & 8.7 & 48.7 & 27.3 & 3.9 & 1.9 & 0.1 & 317 \\
\hline & 6 & 0.0 & 0.1 & 0.4 & 2.5 & 3.1 & 4.1 & 74.1 & 10.9 & 4.4 & 0.4 & 317 \\
\hline & 7 & 0.0 & 0.0 & 0.1 & 0.2 & 0.7 & 0.4 & 11.7 & 69.3 & 16.1 & 1.6 & 317 \\
\hline & 8 & 0.0 & 0.0 & 0.0 & 0.0 & 0.1 & 0.1 & 1.9 & 5.6 & 90.3 & 2.1 & 317 \\
\hline & 9 & 0.0 & 0.0 & 0.0 & 0.0 & 0.0 & 0.0 & 0.2 & 0.6 & 17.4 & 81.8 & 317 \\
\hline \multirow[t]{10}{*}{ SPMS (EDSS score) } & 0 & 100.0 & 0.0 & 0.0 & 0.0 & 0.0 & 0.0 & 0.0 & 0.0 & 0.0 & 0.0 & \\
\hline & 1 & 0.0 & 100.0 & 0.0 & 0.0 & 0.0 & 0.0 & 0.0 & 0.0 & 0.0 & 0.0 & \\
\hline & 2 & 0.0 & 0.0 & 74.4 & 18.7 & 2.1 & 2.8 & 1.8 & 0.1 & 0.1 & 0.0 & 8 \\
\hline & 3 & 0.0 & 0.0 & 0.0 & 70.4 & 15.9 & 3.1 & 9.6 & 0.5 & 0.4 & 0.0 & 85 \\
\hline & 4 & 0.0 & 0.0 & 0.0 & 0.0 & 66.4 & 13.8 & 18.1 & 0.9 & 0.9 & 0.0 & 94 \\
\hline & 5 & 0.0 & 0.0 & 0.0 & 0.0 & 0.0 & 57.4 & 37.4 & 2.6 & 2.6 & 0.0 & 91 \\
\hline & 6 & 0.0 & 0.0 & 0.0 & 0.0 & 0.0 & 0.0 & 87.4 & 4.8 & 7.7 & 0.0 & 331 \\
\hline & 7 & 0.0 & 0.0 & 0.0 & 0.0 & 0.0 & 0.0 & 0.0 & 76.1 & 23.5 & 0.4 & 125 \\
\hline & 8 & 0.0 & 0.0 & 0.0 & 0.0 & 0.0 & 0.0 & 0.0 & 0.0 & 99.6 & 0.4 & 271 \\
\hline & 9 & 0.0 & 0.0 & 0.0 & 0.0 & 0.0 & 0.0 & 0.0 & 0.0 & 0.0 & 100.0 & 15 \\
\hline
\end{tabular}

Data are expressed as percentages

$R R M S$ relapse-remitting multiple sclerosis, EDSS Expanded Disability Status Scale, SPMS secondary progressive multiple sclerosis

analysis are aligned with those submitted and approved by the NICE in England [13].

The DMD-treated cohort is also at risk of discontinuing treatment. Patients discontinue treatment if the DMD does not reduce the frequency or severity of relapses compared with the pretreatment phase, if patients have intolerable adverse effects of the drug, if patients develop an inability to walk (EDSS 6.5-7.0), or if a patient develops SPMS. The annual probabilities of discontinuing treatment were taken from pooled trial data [18]. As guided by input from the $\mathrm{KOL}$, following discontinuation of the drug it is assumed that treatment will consist of BSC, which is aimed at providing temporary relief from the disease (e.g. pain killers) but does not change the course of the disease. Furthermore, patients are at risk of discontinuation from treatment with cladribine and alemtuzumab between the first and second courses. Overall, $4.9 \%$ of patients receiving their first course of cladribine tablets and $2.3 \%$ of patients receiving their first course of alemtuzumab are assumed to discontinue before their second course (in year 2). Patients are subsequently assumed to be 'taking DMDs' until they discontinue due to EDSS progression or development of SPMS. Re-initiation is modeled for alemtuzumab (28\% in year $3,11 \%$ in year 4 , $1 \%$ in year 5). Drug-related adverse events were included in the model, including infusion site reactions, injection site reactions, progressive multifocal leukoencephalopathy (PML), macular oedema, malignancy, hypersensitivity, gastrointestinal disorder, autoimmune thyroid-related events, immune thrombocytopenic purpura, severe infections, and influenza-like symptoms. The list of adverse events was developed following a review of the product characteristics for each drug included in the model, and confirmed by an external advisory panel comprising expert clinicians [30].

\subsubsection{Utilities}

Dutch EQ-5D-3L values for cladribine tablets were derived from the EQ-5D data collected in the CLARITY and CLARITY EXT studies using a Dutch preference set [31]. A systematic literature review was undertaken to identify relevant utility values, alongside the EQ-5D data collected in the CLARITY and CLARITY EXT studies [11, 12]. The model included the impact of disability progression, relapses, and drug-related adverse events on the HRQoL of patients. Additionally, it included the impact of disability on the HRQoL of the caregiver, given the societal perspective as required by the Dutch guidelines for health economic evaluations. A summary of the health state utilities in the base-case model is shown in Table 4. 
Table 4 Summary of health state utilities

\begin{tabular}{|c|c|c|}
\hline Health state & (Dis)utilities (SE) & References \\
\hline Relapse event & $-0.071(0.013)$ & {$[25]$} \\
\hline \multicolumn{3}{|l|}{ Patient health utility } \\
\hline \multicolumn{3}{|l|}{ EDSS } \\
\hline 0 & $0.917(0.021)$ & {$[32]$} \\
\hline 1 & $0.856(0.044)$ & {$[32]$} \\
\hline 2 & $0.816(0.011)$ & {$[32]$} \\
\hline 3 & $0.729(0.011)$ & {$[32]$} \\
\hline 4 & $0.697(0.011)$ & [32] \\
\hline 5 & $0.623(0.023)$ & [32] \\
\hline 6 & $0.548(0.548)$ & [33] \\
\hline 7 & $0.422(0.422)$ & [33] \\
\hline 8 & $0.234(0.234)$ & [33] \\
\hline 9 & $0.005(0.005)$ & [33] \\
\hline SPMS conversion & $0.045(0.021)$ & {$[25]$} \\
\hline \multicolumn{3}{|l|}{ Caregiver disutility } \\
\hline \multicolumn{3}{|l|}{ EDSS } \\
\hline 0 & $-0.002(0.053)$ & {$[34]$} \\
\hline 1 & $-0.002(0.053)$ & {$[34]$} \\
\hline 2 & $-0.002(0.053)$ & {$[34]$} \\
\hline 3 & $-0.045(0.057)$ & {$[34]$} \\
\hline 4 & $-0.142(0.062)$ & {$[34]$} \\
\hline 5 & $-0.160(0.055)$ & {$[34]$} \\
\hline 6 & $-0.173(0.054)$ & [34] \\
\hline 7 & $-0.030(0.038)$ & [34] \\
\hline 8 & $-0.095(0.075)$ & {$[34]$} \\
\hline 9 & $-0.095(0.075)$ & {$[34]$} \\
\hline \multicolumn{3}{|l|}{ Adverse events } \\
\hline Infusion site reaction & $-0.011(0.002)$ & {$[35]$} \\
\hline Injection site reaction & $-0.011(0.002)$ & {$[35]$} \\
\hline PML & $-0.200(0.040)$ & [36] \\
\hline Severe infection & $-0.190(0.038)$ & {$[37]$} \\
\hline Macular oedema & $-0.040(0.008)$ & [36] \\
\hline Gastrointestinal & $-0.240(0.048)$ & {$[36]$} \\
\hline Hypersensitivity & $-0.250(0.050)$ & {$[36]$} \\
\hline Autoimmune thyroid-related event & $-0.110(0.022)$ & {$[36]$} \\
\hline Influenza-like symptoms & $-0.210(0.042)$ & {$[35]$} \\
\hline Malignancy & $-0.116(0.023)$ & {$[38]$} \\
\hline Immune thrombocytopenia purpura & $-0.090(0.018)$ & {$[36]$} \\
\hline
\end{tabular}

Health state utilities are sampled from a log-normal distribution, and the disutility values are sampled from a normal distribution

EDSS Expanded Disability Status Scale, SE standard error, $P M L$ progressive multifocal leukoencephalopathy, SPMS secondary progressive multiple sclerosis

\subsubsection{Costs}

The costs of acquisition, administration, and monitoring were assumed to apply for the duration of time that patients remain on therapy in the model (Tables $5,6,7$ ). For continuously administered therapies, such as natalizumab or fingolimod, the number of people receiving therapy is estimated from the EDSS status of the population, considering those who discontinue (e.g. develop SPMS or discontinue for other reasons) in the previous cycle. All patients were assumed to adhere to therapy and consume the full course of medication in each year. The cost inputs were based on the Dutch costing manual [39], price lists, and Opendisdata [40]. Additional information came from a systematic review of cost studies, additional literature searches, and input from the Dutch KOL in case of unavailable information. For fixed-course therapies, such as alemtuzumab and cladribine tablets, drug costs were estimated based on the proportion of patients eligible for therapy (EDSS $<7.0$ and RRMS) at the start of each cycle multiplied by the proportion treated. The annual drug costs were based on the Dutch list prices, obtained from the Z-index G-Standard of October 2017 [41]. All cost inputs were converted to 2016 costs.

EDSS-related direct medical and non-medical costs, as well as indirect non-medical costs (presented in Table 8), were extracted from the paper from Karampampa et al. [42] and inflated to reflect 2017 values. Indirect unrelated medical costs (medical costs occurring during a lifetime that were unrelated to MS) were calculated by applying the Dutch PAID toolkit version 1.1, which enables the incorporation of future unrelated costs [43].

The costs associated with severe infections, macular edema, gastrointestinal disorder, hypersensitivity reaction, and autoimmune thyroid-related events are available from Opendisdata, a public database including data on average prices paid for healthcare products provided in Dutch hospitals [44]. The costs of infusion-based events are set to zero on the basis that these events would be managed in the day-case setting by delaying or slowing down the infusion rate or through low-cost pain intervention. The cost of these events would therefore be largely covered by the daycase admission. The management of injection site reactions and influenza-like illness are assumed to involve a phone consultation with a district nurse [36]. The average cost of an episode of immune thrombocytopenic purpura (grade III and IV) was obtained from the work of Blommestein et al., assuming the mean duration of an episode was 45 days [45].

The cost for relapses was estimated at $€ 1024$. It was assumed that during relapses, patients visited a neurologist, including 3-day admissions plus administration of methylprednisolone $1 \mathrm{~g}$. These assumptions were validated by the KOL.

\subsection{Sensitivity Analysis}

DSAs were performed to evaluate the impact of uncertainty on the model outcomes, and were performed on the following variables: effect of DMDs on EDSS progression and relapse rate, discontinuation rates, mortality multiplier, 
Table 5 Drug acquisition costs

\begin{tabular}{|c|c|c|c|c|c|c|c|c|}
\hline Therapy & Pack & Unit per pack & Unit cost & Dose & $\begin{array}{l}\text { Unit consumed } \\
\text { per year } 1 / \text { year } 2\end{array}$ & $\begin{array}{l}\text { Total cost } \\
\text { year } 1(€)\end{array}$ & $\begin{array}{l}\text { Total cost } \\
\text { year } 2+{ }^{a} \\
(€)\end{array}$ & References \\
\hline Cladribine tablets & $1 \times 10 \mathrm{mg}$ tablet & 1 & $€ 2785.71$ & $0.875 \mathrm{mg} / \mathrm{kg} / \mathrm{dose}^{\mathrm{a}}$ & $12 / 12$ & 33,780 & 33,780 & [41] \\
\hline Alemtuzumab & $12 \mathrm{mg}$ vial & 1 & $€ 7000.00$ & $12 \mathrm{mg} /$ day & $5 / 3$ & 35,000 & 21,000 & \\
\hline Fingolimod & 28 capsules & 28 & $€ 1695.12$ & 1 tablet/day & 365.25 & 22,112 & 22,112 & \\
\hline Natalizumab & $15 \mathrm{ml}$ vial & 1 & $€ 1594.35$ & $300 \mathrm{mg}$ every month & 13 & 20,727 & 20,727 & \\
\hline
\end{tabular}

${ }^{a}$ Costs for cladribine tablets were for years 1 and 2 only; no additional costs in years 3 and 4 during treatment

Table 6 Drug administration costs

\begin{tabular}{|c|c|c|c|c|c|}
\hline Therapy & Administration & Administration resources consumed per year of therapy & $\begin{array}{l}\text { Total cost } \\
\text { year } 1(€)\end{array}$ & $\begin{array}{l}\text { Total } \\
\text { cost year } \\
2+(€)\end{array}$ & References \\
\hline Cladribine tablets & Oral & No administration requirements & 0 & 0 & [39] \\
\hline Alemtuzumab & Infusion & $\begin{array}{l}5 \times \text { day-case admissions in the first year, plus three } 1 \mathrm{~g} \text { vials of meth- } \\
\text { ylprednisolone, one pack of paracetamol, two packs of acyclovir } \\
(200 \mathrm{mg}) \text {, and five tablets of clemastin; } 3 \times \text { day-case admissions in } \\
\text { subsequent years, plus three } 1 \mathrm{~g} \text { vials of methylprednisolone, one } \\
\text { pack of paracetamol, two packs of acyclovir }(200 \mathrm{mg}) \text {, and five } \\
\text { tablets of clemastin }\end{array}$ & 1507 & 950 & \\
\hline Fingolimod & Oral & Day-case admission in the first year to monitor ECG & 278.49 & 0 & \\
\hline Natalizumab & Infusion & Monthly day-case admissions (13 in total) & 3620 & 3620 & \\
\hline
\end{tabular}

$E C G$ electrocardiagram

baseline characteristics (age, weight), and discounting rates. The effect of DMDs on EDSS progression and relapse rates varied according to the Network meta-analysis (NMA) [18]. The range of variation used in the DSA was $50 \%$ for discontinuation probabilities, baseline sex ratio, and baseline relapse rate in the previous year. Discounting rates varied between 0 and $6 \%$, and baseline characteristics varied using the standard error as provided in the CLARITY study.

In addition, structural sensitivity analyses were performed for alemtuzumab, fingolimod, and natalizumab to test the robustness of the analyses to variations in underlying model assumptions or to the application of alternative grouped input parameters. The following scenarios were considered: the healthcare perspective (excluding both direct non-medical and indirect costs), alternative time horizons (20 and 80 years), and changing the discontinuation probability. In addition, mortality was modeled using the EDSS-specific standardized mortality ratio (SMR) instead of a fixed SMR for MS. Another scenario analysis was run, setting caregiver disutility to zero. Lastly, different waning effect scenarios were conducted for both the HDA and RES subpopulation to analyze the influence of different waning effects of cladribine tablets. Three approaches were considered:
1. Cladribine effect was gradually waned to $0 \%$ after year 6 (assuming full effect until year 2, 75\% effect until year 4 , and $50 \%$ effect until year 6 ).

2. Comparator effect was gradually waned to $0 \%$ after year 6 , keeping cladribine tablets waning the same as the base case.

3. Both cladribine tablets and the comparator effect were gradually waned to $0 \%$ after year 6 .

Lastly, a scenario analysis was included using data from the BCMS registry [21] for both RRMS and SPMS inputs instead of using BCSM registry data for RRMS and the London Ontario Registry [23] data for SPMS.

Probabilistic sensitivity analyses (PSA) were also performed to assess the variation in results stemming from the combined uncertainty in each individual model parameter (Table 9). The input variation per input parameter is provided in the Supplementary Appendix. Finally, a valueof-information (VOI) analysis was conducted, in line with Dutch health economic guidelines [17]. VOI analysis quantifies the value brought by reducing decision uncertainty by means of collecting additional information [46]. 
Table 7 Drug monitoring costs

\begin{tabular}{|c|c|c|c|c|c|}
\hline Therapy & $\begin{array}{l}\text { Monitoring resources consumed in the } \\
\text { first year }\end{array}$ & $\begin{array}{l}\text { Monitoring resources consumed in subse- } \\
\text { quent years }\end{array}$ & $\begin{array}{l}\text { Total cost } \\
\text { year } 1(€)\end{array}$ & $\begin{array}{l}\text { Total } \\
\text { cost year } \\
2+(€)\end{array}$ & References \\
\hline Cladribine tablets & $\begin{array}{l}1 \times \text { MRI scan } \\
3 \times \text { complete blood counts (at months } 2,6 \text {, } \\
\text { and } 12 \text { ) } \\
2 \times \text { neurology visits }\end{array}$ & $\begin{array}{l}2 \times \text { complete blood counts (at months } 14 \\
\text { and } 18 \text { ) } \\
2 \times \text { neurology visits }+1 \times \text { MRI scan }\end{array}$ & 418 & 415 & {$[39,40]$} \\
\hline Alemtuzumab & $\begin{array}{l}12 \times \text { complete blood counts }+1 \times \text { MRI } \\
\text { scan } \\
12 \times \text { biochemistry tests for serum creati- } \\
\text { nine levels } \\
12 \times \text { urinalysis tests with microscopy } \\
4 \times \text { thyroid function tests (thyroid-stimulat- } \\
\text { ing hormone level) } \\
1 \times \text { tuberculin skin test } \\
0.65 \times \text { human papilloma virus test (females } \\
\text { only - assumption } 65 \%) \\
2 \times \text { neurology visits }\end{array}$ & $\begin{array}{l}12 \times \text { complete blood counts } \\
12 \times \text { biochemistry tests for serum creati- } \\
\text { nine levels } \\
12 \times \text { urinalysis tests with microscopy } \\
4 \times \text { thyroid function tests (thyroid-stimulat- } \\
\text { ing hormone level) }+1 \times \text { MRI scan } \\
0.65 \times \text { human papilloma virus test (females } \\
\text { only }- \text { assumption } 65 \% \text { ) } \\
2 \times \text { neurology visits }\end{array}$ & 788 & 770 & \\
\hline Fingolimod & $\begin{array}{l}6 \times \text { complete blood counts (at months } 1,2 \text {, } \\
3,6,9 \text {, and } 12 \text { ) } \\
6 \times \text { biochemistry tests (months } 0,1,3,6 \text {, } \\
9, \text { and } 12 \text { ) } \\
1 \times \text { Ophthalmology assessment } \\
2 \times \text { neurology visits }+1 \times \text { MRI scan } \\
1 \times \text { day-case admission (risk of heart } \\
\text { attack) } \\
1 \times \text { ECG procedure }\end{array}$ & $\begin{array}{l}2 \times \text { complete blood counts (every } \\
6 \text { months) } \\
2 \times \text { biochemistry tests } \\
2 \times \text { neurology visits } \\
1 \times \text { MRI scan }\end{array}$ & 955 & 440 & \\
\hline Natalizumab & $\begin{array}{l}1 \times \text { JC virus test } \\
2 \times \text { biochemistry test } \\
1 \times \text { MRI scan } \\
2 \times \text { neurologist visits }\end{array}$ & $\begin{array}{l}2 \times \mathrm{JC} \text { virus tests }(6 \text {-monthly }) \\
2 \times \text { biochemistry tests } \\
1 \times \text { MRI scan } \\
2 \times \text { neurology visits }\end{array}$ & 458 & 483 & \\
\hline
\end{tabular}

$M R I$ magnetic resonance imaging, ECG electrocardiogram, JC John Cunningham's virus testing

Table 8 Costs by health state

Health state Direct medical Direct non-medi- Indirect noncosts $(€)[35] \quad$ cal costs $(€)[35]$ medical costs $(€)$ [35]

\begin{tabular}{crrr}
\hline EDSS & & & \\
0 & 12,071 & 5301 & 15,754 \\
1 & 12,071 & 5301 & 15,754 \\
2 & 12,071 & 5301 & 15,754 \\
3 & 12,071 & 5301 & 15,754 \\
4 & 14,634 & 16,025 & 24,006 \\
5 & 14,634 & 16,025 & 24,006 \\
6 & 14,634 & 16,025 & 24,006 \\
7 & 14,634 & 16,025 & 24,006 \\
8 & 14,966 & 56,001 & 36,605 \\
9 & 14,966 & 56,001 & 36,605 \\
\hline
\end{tabular}

EDSS Expanded Disability Status Scale

The VOI analysis results are expressed in the population expected value of perfect information (PEVPI), which expresses the value of information considering the number of times the decision has to be made over the lifetime of the technology. Thus, the PEVPI depends on the number of patients who will be treated with cladribine tablets, accounting for the incidence of the decision. In technical terms, based on the PSA outcomes, a per-patient EVPI is calculated as the average of the opportunity losses of all PSA outcomes. This per-patient EVPI is scaled up to a population level EVPI (PEVPI) in order to make it relevant to the decision regarding additional research, using Eq. 1 below, where ' $N_{i}$ ' denotes the relevant number of patients, ' $T$ ' denotes the effective lifetime (in years) for the new product, and ' $a$ ' denotes the discount rate.

PEVPI $=$ EVPI $\times \sum_{i=1}^{T} \frac{N_{i}}{(1+a)^{i}}$

\section{Results}

\subsection{Base-Case Scenario}

An overview of the results of the base-case analyses is given in Table 10, while a breakdown of discounted costs is given 
Table 9 Distributions used for classes of parameters in PSA

\begin{tabular}{ll}
\hline Input & PSA distribution \\
\hline Baseline age & Log-normal \\
Baseline weight distribution & Dirichlet \\
Baseline EDSS distribution & Dirichlet \\
Health state utility & Log-normal \\
Disutilities & Normal \\
AE probabilities & Beta \\
Discontinuation probabilities & Beta \\
Baseline relapse rate & Log-normal \\
Annual reduction in relapse rate & Beta \\
ARR rate ratio & Log-normal \\
Duration of relapse & Log-normal \\
6M-CDP log hazard ratio & Normal \\
HDA/RES progression adjustment factor & Log-normal \\
SMR & Log-normal \\
Time to SPMS & Multivariate normal \\
Costs & Gamma \\
\hline
\end{tabular}

PSA probabilistic sensitivity analysis, EDSS Expanded Disability Scale, $A E$ adverse event, $A R R$ annualized rate, $H D A$ high disease activity, RES rapidly evolving severe, SPMS secondary progressive multiple sclerosis, $S M R$ standardized mortality ratio, $6 M-C D P$ 6-month confirmed disability progression

in Table 11. In the HDA subpopulation, cladribine tablets were the cost-effective (dominant) option compared with alemtuzumab and fingolimod, and also compared with natalizumab in the RES subpopulation. Outcomes are primarily driven by the lower drug cost of cladribine tablets and direct non-medical costs (especially versus fingolimod) rather than differences in efficacy.

\subsection{Sensitivity Analyses}

\subsubsection{Deterministic Sensitivity Analysis}

A deterministic sensitivity analysis (DSA) was performed with a threshold of $€ 50,000 /$ QALY for both the HDA and RES subpopulations (Figs. 2, 3, 4). For all populations, the parameters that exhibited the greatest influence on the basecase results were confirmed disability progression (for cladribine tablets, alemtuzumab, fingolimod and natalizumab) and cost discounting. Importantly, the sensitivity analyses showed that the model is extremely sensitive to the variability in efficacy in terms of disease progression of the drugs.

\subsubsection{Structural Sensitivity Analysis}

Cladribine tablets remained cost effective (dominant) in all structural sensitivity scenarios considered in the HDA population, and remained the cost-effective (dominant) approach for all waning effect scenarios in the HDA population. In the RES population (versus natalizumab) cladribine remained cost effective (dominant) or was less costly and less effective. An overview of the structural sensitivity analyses performed in the model is presented in Table 12.

\subsubsection{Probabilistic Sensitivity Analysis}

The outcomes of the PSA showed that for the HDA population, cladribine tablets were the cost-effective (dominant) strategy when compared with alemtuzumab in $50.9 \%$ of iterations, at a threshold of $€ 50,000 / \mathrm{QALY}$ gained (Fig. 5). Half (47\%) of the iterations were in the south-east quadrant,

Table 10 Results from the base-case analysis

\begin{tabular}{|c|c|c|c|}
\hline HDA population & Cladribine tablets & Alemtuzumab & Fingolimod \\
\hline Total costs & $€ 1,365,355$ & $€ 1,371,105$ & $€ 1,467,052$ \\
\hline Incremental costs (compared with cladribine tablets) & - & $-€ 5939$ & $-€ 101,887$ \\
\hline Total QALYs & 9.318 & 9.219 & 8.333 \\
\hline Incremental QALY (compared with cladribine tablets) & - & 0.099 & 0.985 \\
\hline ICER (compared with cladribine tablets) & - & Dominant & Dominant \\
\hline NMB & - & $€ 10,866$ & $€ 151,115$ \\
\hline RES population & Cladribine tablets & Natalizumab & \\
\hline Total costs & $€ 1,436,038$ & $€ 1,527,896$ & \\
\hline Incremental costs (compared with cladribine tablets) & - & $-€ 91,858$ & \\
\hline Total QALYs & 9.417 & 8.794 & \\
\hline Incremental QALY (compared with cladribine tablets) & - & 0.623 & \\
\hline ICER (compared with cladribine tablets) & - & Dominant & \\
\hline NMB & - & $€ 122,986$ & \\
\hline
\end{tabular}

$H D A$ high disease activity, $Q A L Y s$ quality-adjusted life-years, ICER incremental cost-effectiveness ratio, $N M B$ net monetary benefit, $R E S$ rapidly evolving severe 
Table 11 Breakdown of costs (discounted)

\begin{tabular}{lllr}
\hline HDA population & Cladribine tablets $(€)$ & Alemtuzumab $(€)$ & Fingolimod $(€)$ \\
\hline Drug cost & 64,839 & 65,496 & 107,311 \\
Adverse event cost & 366 & 438 & 374 \\
Relapse and rescue cost & 3968 & 3739 & 4154 \\
Direct medical and non-medical costs & 744,013 & 748,034 & 786,526 \\
Indirect cost & 551,794 & 553,421 & 568,675 \\
Total cost & $1,365,165$ & $1,371,105$ & $1,467,052$ \\
\hline RES population & Cladribine tablets & Natalizumab & 101,572 \\
\hline Drug cost & 63,882 & 327 & 5927 \\
Adverse event cost & 366 & 814,243 \\
Relapse and rescue cost & 5851 & 585,741 \\
Direct medical and non-medical costs & 789,201 & $1,527,896$ \\
Indirect cost & 575,951 & $1,436,038$ & \\
Total cost & &
\end{tabular}

$H D A$ high disease activity, RES rapidly evolving severe

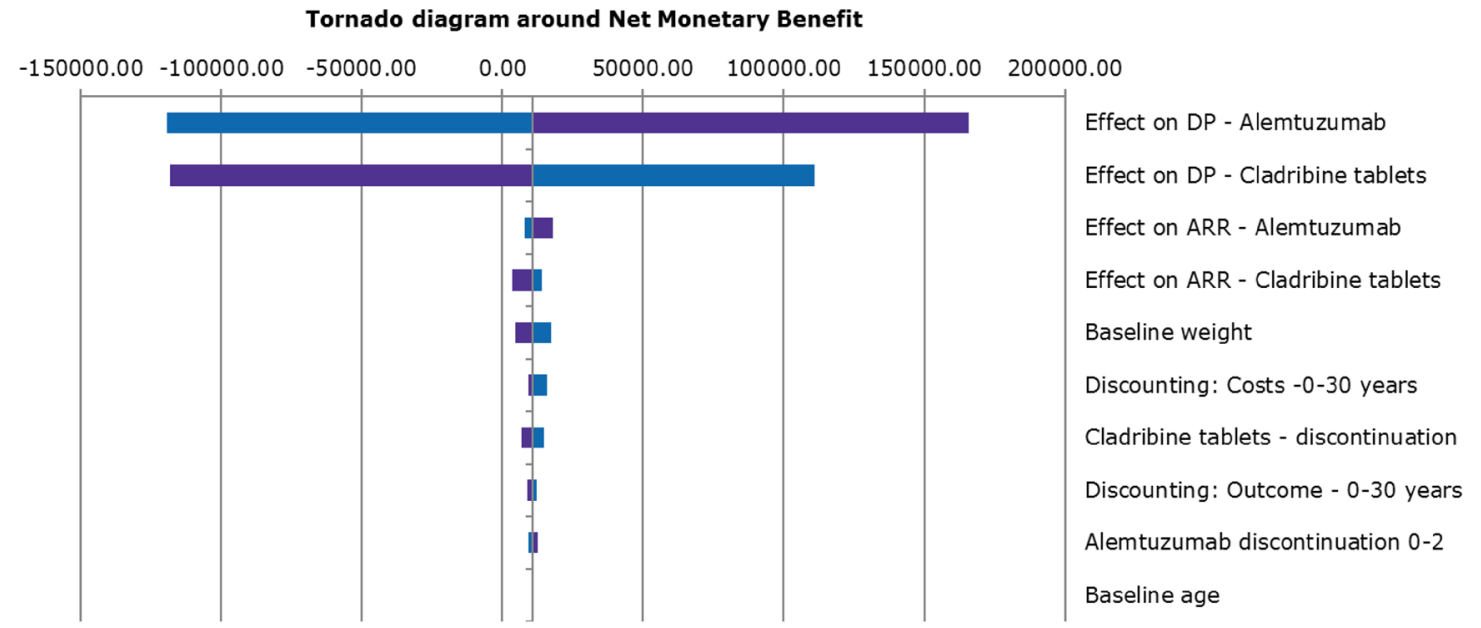

DP: Disability progression, ARR: Annualized Relapse Rate.

Fig. 2 Tornado diagram around net monetary benefit (cladribine tablets vs. alemtuzumab)

and half $(47 \%)$ were in the north-west quadrant. This reflects the uncertainty around the base-case results, and, as such, cladribine tablets should be considered at parity with alemtuzumab. When compared with fingolimod, cladribine tablets were the cost-effective (dominant) strategy, with a $98.2 \%$ probability of being cost effective at a threshold of $€ 50,000 /$ QALY gained (Fig. 6). Almost all iterations were in the south-east quadrant, indicating the robustness of the analysis. For the RES population, when comparing against natalizumab, cladribine tablets were the cost-effective (dominant) strategy, with a $94.1 \%$ probability of being cost effective at a threshold of $€ 50,000 / Q A L Y$ gained (Fig. 7).

\subsection{Value-of-Information Analysis}

The number of patients eligible for treatment with cladribine tablets in The Netherlands was estimated at 383, based on the Dutch population [47] and MS prevalence in Flanders, Belgium [48]. Uptake was estimated at $30 \%$, which is the expected market share in the first year, as verified by the Dutch Healthcare Institute (Zorginstituut Nederland), resulting in a PEVPI of $€ 19,295,441$. Given the high impact that the estimated uptake has on the calculation of the PEVPI, alternative values for the uptake were explored. The different uptake scenarios give the following outcomes: using an uptake of 10\% (38 patients treated in The Netherlands), the 


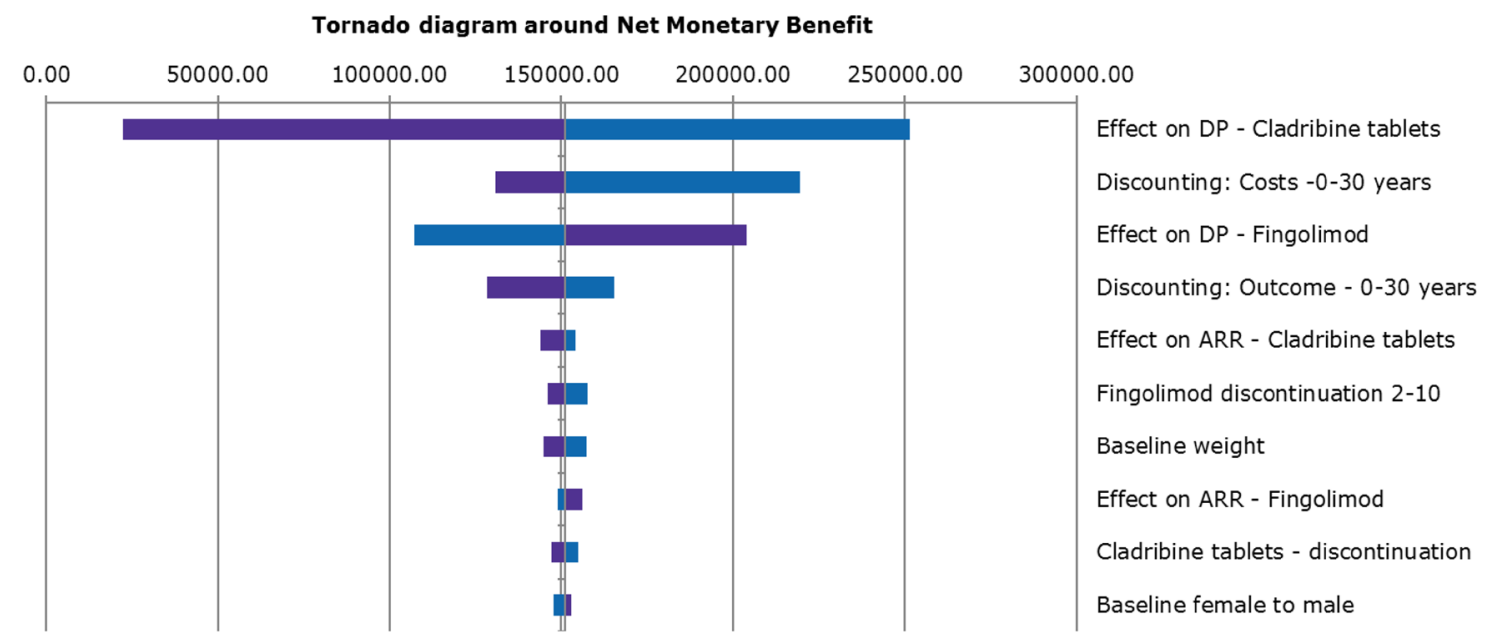

DP: Disability Progression, ARR: Annualized Relapse Rate.

Fig. 3 Tornado diagram around net monetary benefit (cladribine vs. fingolimod)

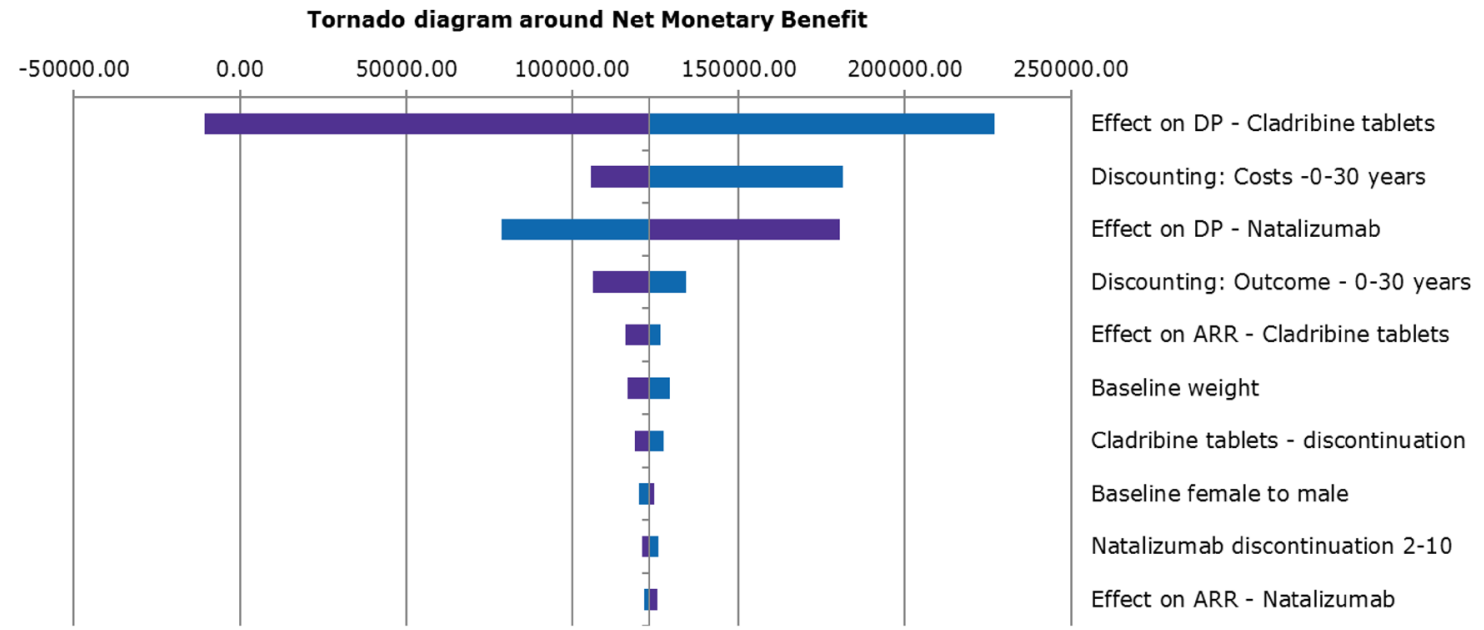

DP: Disability Progression, ARR: Annualized Relapse Rate.

Fig. 4 Tornado diagram around net monetary benefit (cladribine vs. natalizumab)

PEVPI was estimated to be $€ 6,431,814$; with an uptake of $20 \%$ (77 patients), the PEVPI was $€ 12,863,627$; and with a $50 \%$ uptake, the PEVPI amounted to $€ 32,159,068$

\section{Discussion}

This paper reports on the cost effectiveness, from the Dutch context, of cladribine tablets versus alemtuzumab and fingolimod in the RRMS HDA patient population, and versus natalizumab in the RRMS RES subpopulation. It details a comparison between the costs and effects of the alternative treatments using a cohort-based, multi-state Markov transition model. The choice of this model is in accordance with the majority of models used in economic analyses of cost effectiveness of disease-modifying therapies in MS. More specifically, 24 of 33 studies included in the systematic literature review of Iannazzo et al. used the Markov transition model [49]. The model was based on a previously constructed UK model that used 11 health states [13], thus assuming no differences in progression rates and quality of life between patients in RRMS or SMPS. In the current model, a 21-health-state structure was applied that does allow differences between RRMS and SMPS. Applying this 21-state model was based on the recommendation and opinion of the Dutch KOL. 
Table 12 Overview of structural sensitivity analyses performed in the model

\begin{tabular}{llll}
\hline & vs. alemtuzumab & vs. fingolimod & vs. natalizumab \\
\hline Healthcare perspective & Cladribine dominant & Cladribine dominant & Cladribine dominant \\
Time horizon of 20 years & Cladribine dominant & Cladribine dominant & Cladribine dominant \\
Time horizon of 80 years & Cladribine dominant & Cladribine dominant & Cladribine dominant \\
Alternative discontinuation probability & Cladribine dominant & Cladribine dominant & Cladribine dominant \\
Mortality modeled using EDSS-specific SMRs & Cladribine dominant & Cladribine dominant & Cladribine dominant \\
Caregiver disutility set to zero & Cladribine dominant & Cladribine dominant & Cladribine dominant \\
Cladribine effect was gradually waned to 0\% after year 6 & Cladribine dominant & Cladribine dominant & Cladribine less costly and less effective \\
$\begin{array}{l}\text { (assuming full effect until year 2, 75\% effect until year 4, } \\
\text { and 50\% effect until year 6) }\end{array}$ & & \\
$\begin{array}{l}\text { Comparator effect was gradually waned to 0\% after year } \\
\text { 6, continually waning cladribine tablets the same as the }\end{array}$ & Cladribine dominant & Cladribine dominant & Cladribine dominant \\
base case & & & \\
$\begin{array}{l}\text { Both cladribine tablets and comparator effect were gradu- } \\
\text { ally waned to 0\% after year 6 }\end{array}$ & Cladribine dominant & Cladribine dominant & Cladribine less costly and less effective \\
$\begin{array}{l}\text { Using data from the study by Palace et al. [21] for both the } \\
\text { RRMS and SPMS inputs }\end{array}$ & Cladribine dominant & Cladribine dominant & Cladribine dominant \\
\hline
\end{tabular}

SPMS secondary progressive multiple sclerosis, $S M R$ standardized mortality ratio, EDSS Expanded Disability Scale, $R R M S$ relapsing-remitting multiple sclerosis

Panel A: CE plane-incremental costs and QALYs

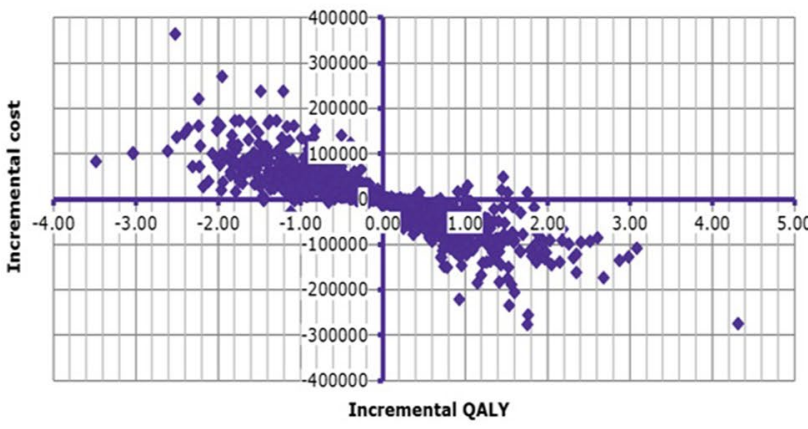

Panel B: CE acceptability curve

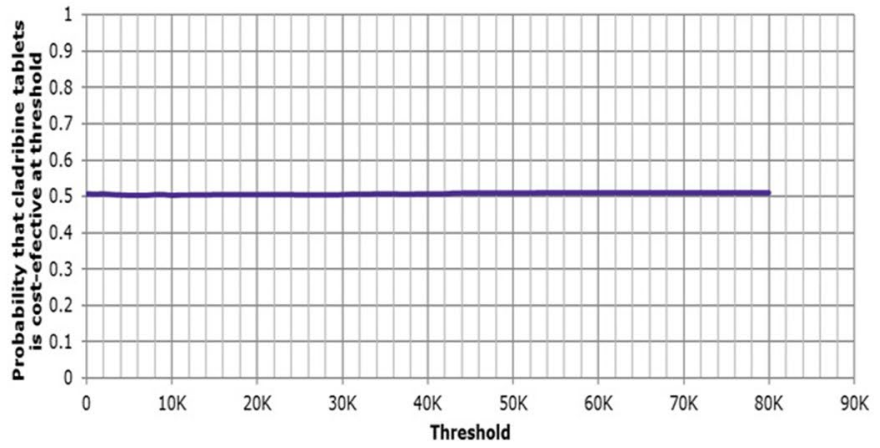

Fig. 5 Cladribine tablets vs. alemtuzumab (high disease activity population)

Panel A: CE plane-incremental costs and QALYS

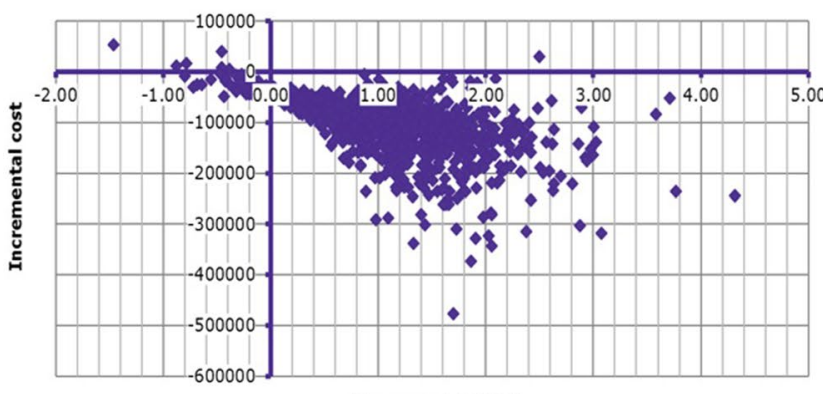

Incremental QALY
Panel B: CE acceptability curve

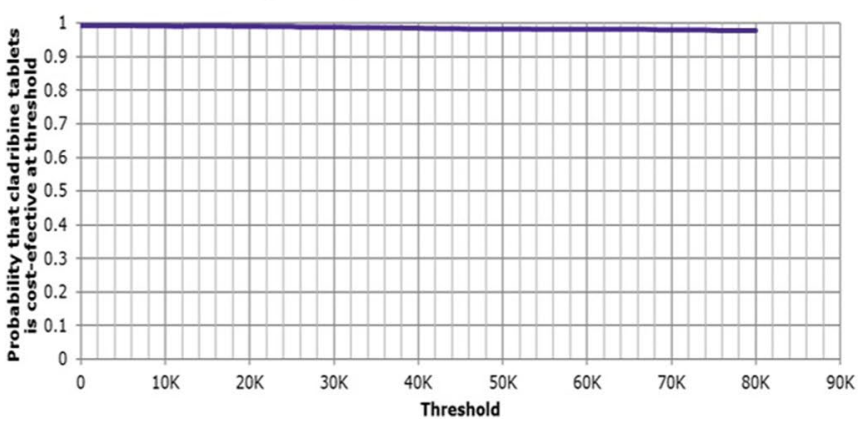

Fig. 6 Cladribine tablets vs. fingolimod (high disease activity population) 
Panel A: CE plane-incremental costs and QALYS

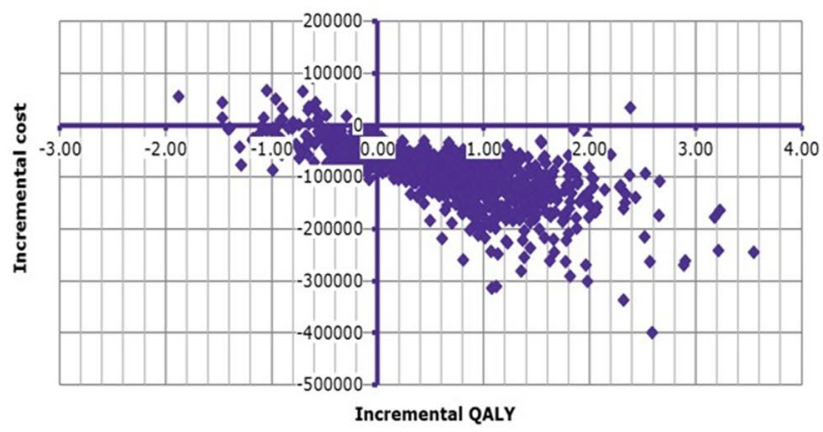

Fig. 7 Cladribine tablets vs. natalizumab (RES population)

The results of the base-case analysis demonstrated that cladribine tablets were cost effective versus alemtuzumab and fingolimod in the HDA patient population, and versus natalizumab in the RES patient population, at a willingness-to-pay threshold of $€ 50,000$. It seems that this is largely attributable to the lower cost of cladribine tablets. The treatment of RRMS in the HDA subgroup has the potential to provide significant cost savings when used instead of alemtuzumab and fingolimod, with an NMB of $€ 10,866$ and $€ 151,115$, respectively. In addition, the treatment of RES RRMS with cladribine tablets instead of natalizumab in this subgroup has the potential to provide cost savings, with an NMB of $€ 122,986$. The DSAs demonstrated that the evaluation is extremely sensitive to treatment effect on confirmed disability progression in both scenarios, which shows that there is strong uncertainty around the relative effectiveness. The PSA for both scenarios (HDA and RES subpopulations) showed significant overlap in the credible intervals for total lifetime QALY outcomes and costs for cladribine tablets and all relevant comparators, which further highlights the uncertainty present. The probability that cladribine tablets are a cost-effective treatment option for HDA patients compared with alemtuzumab and fingolimod was $50.9 \%$ and $98.2 \%$, respectively, and $94.1 \%$ for RES patients compared with natalizumab. Note that the PSA outcomes against alemtuzumab demonstrated considerable uncertainty. Overall, $47 \%$ of iterations were in the north-west quadrant, i.e. dominated, and $47 \%$ were in the south-east quadrant, i.e. dominant. The results of the PSA indicate that despite the dominance of cladribine in the base-case, these treatments (cladribine tablets and alemtuzumab) should be considered at parity.

Our results are in line with findings of other researchers suggesting that cladribine is cost effective for the treatment of HDA RRMS patients, and is therefore recommended for reimbursement. In England, cladribine tablets were dominant versus alemtuzumab and natalizumab in pairwise comparisons. Cladribine tablets had a $93 \%$ probability of being
Panel B: CE acceptability curve

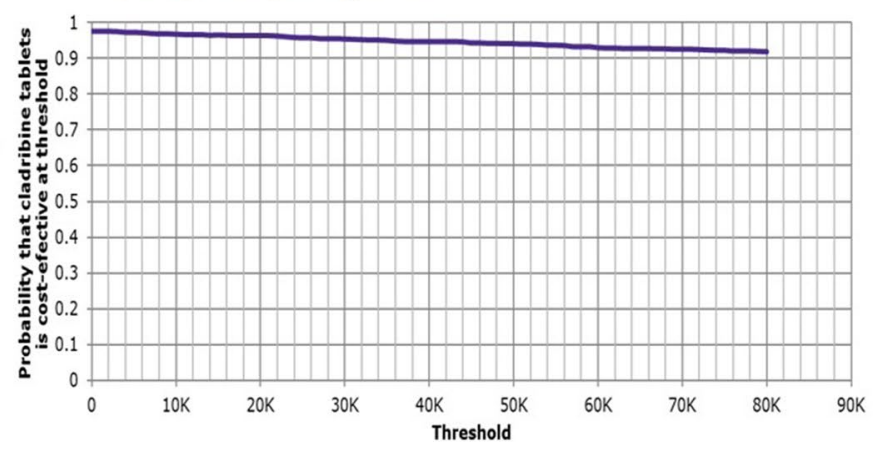

cost effective at a threshold of $£ 30,000 / \mathrm{Q} A L Y$ gained [13]. In Bulgaria, cladribine tablets were considered a cost-effective therapeutic option compared with alemtuzumab (incremental cost-effectiveness ratio = Bulgarian Lev 663.03/ QALY) [50]. The cost effectiveness of cladribine for the treatment of adult patients with HDA RRMS, defined by clinical or imaging features, also suggested that cladribine is considered cost effective. Cladribine was cost saving versus all alternative strategies, with incremental costs ranging from $-€ 60,604$ (alemtuzumab) to $-€ 176,902$ (natalizumab) [51].

There are some limitations regarding the analyses conducted. The PSA for both scenarios (HDA and RES subpopulations) showed significant overlap in the credible intervals for total lifetime QALY outcomes and costs for cladribine tablets and all relevant comparators, which highlights the uncertainty present. Another important limitation is that there is a serious lack of head-to-head trials in the disease area of MS. All efficacy comparisons in the model are therefore based on NMA and meta-regression. In addition, the analyses in the HDA and RES populations consisted of post hoc, subgroup analysis. The intention-to-treat population of the CLARITY studies consisted of RRMS patients and was not restricted to patients with HDA or RES. These post hoc analyses were requested by the EMA, although they are an important additional source of uncertainty. In addition, some health technology assessment (HTA) agencies were critical about the network meta-regression approach (NICE and the Scottish Medicine Consortium [SMC]). The NICE committee concluded that even though there is not enough evidence to determine whether cladribine is more or less effective than other treatments, it is cost effective compared with all other treatments and was therefore recommended [52]. Additionally, despite their criticism regarding the indirect comparison, the SMC concluded that "the economic case has been demonstrated" [53]. Outside of the UK assessments, other HTA bodies accepted this approach, such as the European Network for Health Technology Assessment 
[54], the National Centre for Pharmacoeconomics (NCPE) in the Republic of Ireland [51], and the Tandvårds-Läkemedelförmånsverket (TLV) in Sweden [55], and concluded that cladribine is cost effective compared with the alternative options. Nevertheless, given these serious limitations and the strong uncertainty, all outcomes presented in this paper should be interpreted with caution. To limit the complexity of the model, it was assumed that patients received no further DMD treatment after cessation of therapy. However, this may not reflect current clinical practice and is a well-known limitation of MS models. Moreover, the model was constructed based on clinical efficacy and safety data from clinical trials that differ in many aspects, including study design, population characteristics, and the long time frame over which the data were collected (1990s to 2012). All scenario analyses performed are subject to the limited availability of 6-month confirmed disability progression data for comparator therapies.

A key strength of this study is that the model considers cost effectiveness across two subpopulations of MS. Moreover, the study included a VOI analysis quantifying the value of reducing uncertainty in the model. In addition, several relevant scenario analyses were conducted, including a waning effect scenario analysis.

\section{Conclusions}

The treatment of RRMS patients with cladribine tablets seems cost effective versus alemtuzumab and fingolimod in HDA patients, and versus natalizumab in RES patients, at a threshold of $€ 50,000 / Q A L Y$ gained. Driven by the lower costs, cladribine tablets were cost effective (dominant) in all base-case analyses. Nevertheless, given that outcomes are based on indirect comparisons and post hoc subgroup analysis, and the considerable uncertainty surrounding the outcomes, the results presented in this paper should be interpreted with caution.

Author contributions SB was responsible for development of the global cost-effectiveness model and contributed to the design of the Dutch model adaptation. MDF and KM contributed to the Dutch model adaptation. REM provided support in the model study design and writing of the manuscript. GJDH contributed to the model design and study design, and supported the writing of the manuscript. KMH Schiffers and GH contributed to the overall study design and supported the writing of the manuscript. MK was the overall guarantor of the study. All authors reviewed and approved the manuscript.

\section{Compliance with Ethical Standards}

Funding Merck B.V., The Netherlands, provided funding to IQVIA for data acquisition and analysis.
Conflict of interest Marieke Krol is a former employee, and Krijn M. H. Schiffers is a current employee, of Merck B.V., Schiphol-Rijk, The Netherlands, an affiliate of Merck KGaA, Darmstadt, Germany. Gerard Harty is an employee of EMD Serono, Inc., a business of Merck KGaA Darmstadt, Germany. Maria de Fransesco, Koshu Mahajan, Renée Else Michels, Gerald J. D. Hengstman, and Sangeeta Budhia report no further conflicts of interest.

Data availability statement The datasets generated and/or analyzed during the current study are available from the corresponding author upon reasonable request.

Open Access This article is distributed under the terms of the Creative Commons Attribution-NonCommercial 4.0 International License (http://creativecommons.org/licenses/by-nc/4.0/), which permits any noncommercial use, distribution, and reproduction in any medium, provided you give appropriate credit to the original author(s) and the source, provide a link to the Creative Commons license, and indicate if changes were made.

\section{References}

1. Zuvich RL, McCauley JL, Pericak-Vance MA, Haines JL. Genetics and pathogenesis of multiple sclerosis. Semin Immunol. 2009;21(6):328-33.

2. Kramer MA, van der Maas NA, van Soest EM, Kemmeren JM, de Melker HE, Sturkenboom MC. Incidence of multiple sclerosis in the general population in the Netherlands. Neuroepidemiology. 2012;39(2):96-102.

3. National MS Society. Types of MS: relapsing-remitting MS (RRMS). 2015. https://www.nationalmssociety.org/What-is-MS/ Types-of-MS/Relapsing-remitting-MS. Accessed 3 Jan 2018.

4. Lublin FD, Reingold SC, Cohen JA, Cutter GR, Soelberg Sørensen P, Thompson AJ, Wolinsky JS, et al. Defining the clinical course of multiple sclerosis: the 2013 revisions. Neurology. 2014;83(3):278-86.

5. Hauser SL, Oksenberg JR. The neurobiology of multiple sclerosis: genes, inflammation, and neurodegeneration. Neuron. 2006;52(1):61-76.

6. Compston A, Coles A. Multiple sclerosis. Lancet. 2002;359:1221-31.

7. Tullman MJ. Overview of the epidemiology, diagnosis, and disease progression associated with multiple sclerosis. Am J Manag Care. 2013;19(2 Suppl):S15-20.

8. Milo R, Kahana E. Multiple sclerosis: geoepidemiology, genetics and the environment. Autoimmun Rev. 2010;9(5):A387-94.

9. Richtlijnen database. 2012. Multipele Sclerose. Richtlijnen Database. https://richtlijnendatabase.nl/richtlijn/multipele_sclerose/ multipele_sclerose_-_startpagina.html. Accessed 1 Mar 2018.

10. Montalban X, Gold R, Thompson AJ, Otero-Romero S, Amato MP, Chandraratna D, Clanet M, Comi G, et al. ECTRIMS/EAN guideline on the pharmacological treatment of people with multiple sclerosis. Mult Scler J. 2018;24(2):96-120.

11. EMD Serono. A Safety and efficacy study of oral cladribine in subjects with relapsing-remitting multiple sclerosis (RRMS) (CLARITY). ClinicalTrials.gov. 2014. https://clinicaltrials.gov/ ct2/show/NCT00213135. Accessed 2 May 2018.

12. EMD Serono. CLARITY extension study. ClinicalTrials.gov. 2014. https://clinicaltrials.gov/ct2/show/NCT00641537. Accessed 1 May 2018.

13. Hettle R, Harty G, Wong SL. Cost-effectiveness of cladribine tablets, alemtuzumab, and natalizumab in the treatment of 
relapsing-remitting multiple sclerosis with high disease activity in England. J Med Econ. 2018;21(7):676-86.

14. Farmacotherapeutisch kompas. Multiple sclerose. 2017. https:// www.farmacotherapeutischkompas.nl/bladeren/indicatieteksten/ multipele_sclerose. Accessed 1 Jan 2017.

15. Kurtzke JF. Rating neurologic impairment in multiple sclerosis: an expanded disability status scale (EDSS). Neurology. 1983;33(11):1444-52.

16. National Institute for Health and Care Excellence. TA32: Beta interferon and glatiramer acetate for the treatment of multiple sclerosis. 2002. https://www.nice.org.uk/Guidance/TA32. Accessed 2 July 2015.

17. Zorginstituut Nederland. Richtlijn voor het uitvoeren van economische evaluaties in de gezondheidszorg (verdiepingsmodules). Bijlage 3. Zorginstituut Nederland. 2016. https://www.zorginstit uutnederland.nl/publicaties/publicatie/2016/02/29/richtlijn-voorhet-uitvoeren-van-economische-evaluaties-in-de-gezondheidszorg . Accessed 1 May 2018.

18. ZIN: Zorginstituut Nederland. Kosteneffectiviteit in de praktijk. 2015. https://www.zorginstituutnederland.nl/publicaties/rappo rt/2015/06/26/kosteneffectiviteit-in-de-praktijk. Accessed 4 Feb 2018.

19. Siddiqui MK, Khuruna IS, Budhia S, Hettle R, Harty G, Wong SL. Systematic literature review and network meta-analysis of cladribine tablets versus alternative disease-modifying treatments for relapsing-remitting multiple sclerosis. Curr Med Res Opin. 2018;34(8):1361-71.

20. Berardi A, Siddiqui MK, Treharne C, Harty G, Wong SL. Estimating the comparative efficacy of cladribine tablets versus alternative disease modifying treatments in active relapsing-remitting multiple sclerosis: adjusting for patient characteristics using metaregression and matching-adjusted indirect treatment comparison approaches. Curr Med Res Opin. 2019;35(8):1371-8.

21. Palace J, Bregenzer T, Tremlett H, Oger J, Zhu F, Boggild M, et al. UK multiple sclerosis risk-sharing scheme: a new natural history dataset and an improved Markov model. BMJ Open. 2014;4(1):e004073.

22. Koch M, Kingwell E, Rieckmannn P, Tremlett H. The natural history of secondary progressive multiple sclerosis. J Neurol Neurosurg Psychiatry. 2010;81(9):1039-43.

23. Ebers G. Natural history of multiple sclerosis. J Neurol Neurosurg Psychiatry. 2001;71 Suppl:9916-ii16.

24. Ruutiainen J, Viita AM, Hahl J, Sunell J, Nissinen H. Burden of illness in multiple sclerosis (DEFENSE) study: the costs and quality of life of Finnish patients with multiple sclerosis. J Med Econ. 2016;19(1):21-33.

25. Orme M, Kerrigan J, Tyas D, Russel N, Nixon R. The effect of disease, functional status, and relapses on the utility of people with multiple sclerosis in the UK. Value Health. 2007;10(1):54-60.

26. Tremlett H, Zhao Y, Rieckmann P, Hutchinson M. New perspectives in the natural history of multiple sclerosis. Neurology. 2010;74(24):2004-15

27. Trogdon JG, Ekwueme Du, Chamiec-Case L, Guy GP. Breast cancer in young women: health state utility impacts by race/ethnicity.”. Am J Prev Med. 2016;50(2):262-9.

28. CBS. Statline. Gezonde levensverwachting vanaf 1981. 2016. https://opendata.cbs.nl/statline/\#/CBS/nl/dataset/71950ned/table ?ts $=1523890269890$.

29. Bronnum-Hansen H, Koch-Henriksen N, Stenager E. Trends in survival and cause of death in Danish patients with multiple sclerosis. Brain. 2004;127(Pt 4):844-50.

30. European Medicines Agency. Annex 1: summary of product characteristics. 2017. http://www.ema.europa.eu/docs/en_GB/ document_library/EPAR_-_Product_Information/human/00423 0/WC500234561.pdf.
31. Versteegh M, et al. Dutch tariff for the five-level version of the EQ-5D. Value Health. 2016;19:343-52.

32. Giovannoni G, Comi G, Cook S, Rammohan K, Rieckmann P, Soelberg S, et al. A placebo-controlled trial of oral cladribine for relapsing multiple sclerosis. N Engl J Med. 2010;362(5):416-26.

33. Kobelt G, Berg J, Lindgren P, Anten B, Ekman M, Jongen PJ, et al. Costs and quality of life in multiple sclerosis in the Netherlands. Eur J Health Econ. 2006;7(Suppl 2):S55-64.

34. Acaster S, Perard R, Chauhan D, Lloyd AJ. A forgotten aspect of the NICE reference case: an observational study of the healthrelated quality of life impact on caregivers of people with multiple sclerosis. BMC Health Serv Res. 2013;13(1):346.

35. Boye KS, Matza LS, Walter KN, Van BK, Palsgrove AC, Tunan A. Utilities and disutilities for attributes of injectable treatments for type 2 diabetes. Eur J Health Econ. 2011;12(3):219-30.

36. National Institute for Health and Care Excellence. Alemtuzumab for treating relapsing-remitting multiple sclerosis. NICE guidance. 2014. https://www.nice.org.uk/guidance/ta312/resources/ alemtuzumab-for-treating-relapsingremitting-multiple-sclerosispdf-82602423084229. Accessed 1 Mar 2018.

37. Shingler S, Fordham B, Evans M, Schroeder M, Thompson G, Dewilde $S$, et al. Utilities for treatment-related adverse events in type 2 diabetes. J Med Econ. 2015;12(3):45-55.

38. Brown DS, Trogdon JG, Ekwueme DU, Chamiec-Case L, Guy GP Jr, Tangka FK, et al. Health state utility impact of breast cancer in US women aged 18-44 years. Am J Prev Med. 2016;50(2):255-61.

39. Hakkaart-van Roijen L, van der Linden N, Bouwmans C, Kanter T, Tan SS. Cost-effectiveness of cladribine tablets, alemtuzumab, and natalizumab in the treatment of relapsing-remitting multiple sclerosis with high disease activity in England. Rotterdam: Zorginstituut Nederland; 2016.

40. NZA. Opendisdata. 2018. http://www.opendisdata.nl/. Accessed 4 Feb 2018.

41. Z-index. 2017. https://www.z-index.nl/g-standaard. Accessed 31 Oct 2017.

42. Karampampa K, Gustavsson A, van Munster ET, Hupperts RM, Sanders EA, Mostert J, Sinnige OL, et al. Treatment experience, burden, and unmet needs (TRIBUNE) in multiple sclerosis study: the costs and utilities of MS patients in the Netherlands. J Med Econ. 2013;16(7):939-50.

43. van Baal PHM, Wong A, Slobbe LCJ, Polder JJ, Brouwer WBF, de Wit GA. Standardizing the inclusion of indirect medical costs in economic evaluations. Pharmacoeconomics. 2011;29(3):175-87.

44. Nederlandse zorgautoriteit. Zorgproducten. DBC-Informatiesysteem. 2014-2018. http://www.opendisdata.nl/.

45. Blommestein HM, de Groot $\mathrm{S}$, Aarts MJ, Vemer P, de Vries R, van Abeelen AF, et al. Cost-effectiveness of obinutuzumab for chronic lymphocyticleukaemia in The Netherlands. Leukemia Res. 2016;50:37-45.

46. Briggs A, Claxton K, Sculpher M. Decision modelling for health economic evaluation. Oxford: Oxford University Press; 2006.

47. CBS. Statline. Geslacht, leeftijd en burgelijke staat. 2017. https:// opendata.cbs.nl/statline/\#/CBS/nl/dataset/37325/table?ts=15295 01336165 .

48. Kingwell E, Marriot JJ, Jetté N, Pringsheim T, Makhani N, Morrow SA, et al. Incidence and prevalence of multiple sclerosis in Europe: a systematic review. BMC Neurol. 2013;13:128.

49. Iannazzo S, Iliza AC, Perrault L. Disease-modifying therapies for multiple sclerosis: a systematic literature review of cost-effectiveness studies. Pharmacoeconomics. 2018;36(2):189-204.

50. Djambazov S, Slavchez G, Dineva T, Panayotov P, Vekov T. Cost-effectiveness analysis of cladribine tablets for treatment of patients with relapsing-remitting multiple sclerosis in Bulgaria. Value Health. 2018;21(Suppl 1):S206. 
51. National Centre for Pharmacoeconomics. Cost-effectiveness of cladribine $\left(\right.$ Mavenclad $\left.^{\circledR}\right)$ for the treatment of adult patients with highly active relapsing multiple sclerosis (MS) as defined by clinical or imaging features. 2018. http://www.ncpe.ie/wp-conte nt/uploads/2017/09/Summary-cladribine.pdf.

52. National Centre for Pharmacoeconomics. Cladribine tablets for treating relapsing-remitting multiple sclerosis. Technology appraisal guidance TA493. 2018. https://www.nice.org.uk/Guida nce/TA493. Accessed 2 Apr 2019.

53. Scottish Medicine Consortium. Cladribine $10 \mathrm{mg}$ tablet $\left(\right.$ Mavenclad $^{\circledR}$ ). SMC No. 1300/18. 2018. https://www.scottishme dicines.org.uk/medicines-advice/cladribine-mavenclad-fullsubmis sion-130018/. Accessed 2 Apr 2019.
54. Zorginstituut Nederland. Wijziging bijlage 2 voorwaarde fingolimod (Gilenya). Zorginstuut Nederland. 2016. https://www. zorginstituutnederland.nl/publicaties/rapport/2016/07/12/wijzi ging-bijlage-2-voorwaarde-fingolimod-gilenya-bij-actieve-relap se-remitting-multiple-sclerose-rrms. Accessed 1 Mar 2018.

55. Tandvårds-Läkemedelförmånsverket. Mavenclad ingår i högkostnadsskyddet". 2018. https://www.tlv.se/beslut/beslut-lakemedel/ generell-subvention/arkiv/2018-03-28-mavenclad-ingar-i-hogko stnadsskyddet.html. Accessed 2 Feb 2019. 